\title{
Progress in Teachers' Readiness to Promote Positive Youth Development among Students during the Lions Quest Teaching Workshop
}

\author{
Markus Talvio ${ }^{1}$, Minna Berg ${ }^{1}$, Elina Ketonen ${ }^{1}$, Erkki Komulainen ${ }^{1}$, Kirsti Lonka ${ }^{1}$ \\ ${ }^{1}$ Department of Teacher Education, University of Helsinki, Finland \\ Correspondence: Markus Talvio, C/O Kirsti Lonka, PO Box 9, 00014 University of Helsinki, Finland
}

Received: July 13, 2015 Accepted: July 31, $2015 \quad$ Online Published: August 10, 2015

doi:10.11114/jets.v3i6.869 URL: http://dx.doi.org/10.11114/jets.v3i6.869

\begin{abstract}
Modern learning psychology places an emphasis on the ability of teachers to promote their students' social and emotional learning (SEL) and living a good life. Research on precisely how teachers promote SEL and well-being among their students, however, remains scarce. This study focused on evaluating the Lions Quest teaching workshop (LQ), which aims to improve the knowledge and skills of teachers in SEL and to promote a healthy and meaningful life among students.

In total, 153 Finnish teachers participated in LQ. We compared these to 61 Finnish teachers who did not participate in the LQ training as well as a second comparison group consisting of 46 Finnish teachers to investigate the possible effects of pre-testing. We collected data from the intervention group before and after the training and from the first comparison group at approximately the same time points. Data from the second comparison group was collected only once. Using the repeated measures general linear model, we analyzed teachers' readiness to promote the LQ goals from two perspectives, namely from participants' experienced importance of those goals and their perceived competence in promoting them. In addition, we evaluated task values among participants.
\end{abstract}

Teachers participating in LQ rated the goals as more important and relevant after receiving training. Furthermore, participants from the intervention group felt more competent in skills related to the LQ goals than the comparison groups.

This study adds to both the theoretical and practical development of teachers' skills in contemporary contexts.

Keywords: social and emotional learning (SEL), Lions Quest (LQ), service learning, health promotion, continuing education, teacher training

\section{Introduction}

Teaching practices require continual development to face the challenges of an invariably changing world. Today, for example, based on recent research from educational psychology $21^{\text {st }}$ century skills (Ananiadou \& Claro, 2009) highlight the necessity of reviewing classroom pedagogy. One typical way in which teachers update their skills during their careers includes completing continuing education and training programs. However, many factors determine teacher participation in follow-up courses. School administrations may organize trainings inviting all staff members to participate. In Finland, however, teachers select parts of courses to attend based on their perceived importance and their personal interests. As such, teachers attending trainings are motivated. On the other hand, some courses may be unattractive to teachers, particularly if the topic is unfamiliar to participants. Thus, it is important that the development of the school's know-how depends not only on the interests of its teachers, but also on its future needs.

Following from the positive psychology movement, recommendations increasingly encourage developing teachers' social and emotional learning (SEL) as a part their expertise (Humphrey, 2013). However, teacher training on SEL has not been systematic, instead being offered primarily as follow-up training for volunteer teachers. In this study, we investigated teacher preconceived notions, expectations and perceived competencies before and during a school training program on youth development and SEL, namely, Lions Quest (LQ).

\subsection{Social and Emotional Learning (SEL) and Lions Quest (LQ)}

SEL refers to a process aimed at developing skills for life effectiveness which aim to help individuals handle themselves in their relationships and at work. SEL consists of recognizing and managing emotions, developing a caring attitude 
towards others, creating positive relationships, making responsible decisions and handling challenging situations constructively (Collaborative for academic, social and emotional learning, 2014). According to Humphrey (2013), developmental psychology models for social and emotional competence and the application of emotional intelligence theory and research in education form the basis of the theory of SEL. A meta-analysis by Durlak and colleagues (2011) revealed that a pupil-specific SEL program improved social and emotional skills and attitudes towards school, increased positive behaviors, reduced emotional distress and problematic conduct and ultimately improved academic performance among students.

In recent years, interest on SEL among educational policy makers, practitioners and researchers has increased. For example, the U.S. House of Representatives recently introduced a landmark bill to change federal educational policy to promote SEL (Humphrey, 2013). Similarly in Finland, the National Board of Education presented a new curriculum plan for 2016 that stresses recognizing one's feelings, managing one's self, developing social interaction skills and making responsible and ethical decisions, all of which mirror components of SEL (The Finnish National Board of Education, 2014).

Lions Quest (LQ) is an SEL program that has gained widespread international application. According to the LQ website, it is now available in 90 countries. During its 25 years of existence, more than 13 million pupils have participated in LQ with more than half a million teachers implementing LQ in their classrooms (Lions Quest, 2015). Originally an alcohol and drug prevention program (Talvio \& Lonka, 2013), today LQ primarily aims to support positive youth development in school settings through health promotion, strengthening SEL and emphasizing service. In addition to studying SEL skills in the classroom, LQ promotes the creation of a safe learning environment, encourages the maintenance of solid connections to pupils' families and networks beyond school and encourages the entire school community to learn in order to serve others. To maintain the quality of LQ, teachers must participate in the LQ teacher workshop which provides the tools necessary to apply LQ to work settings.

Creating a solid learning community, promoting SEL, learning to conduct an LQ lesson through the use of specific materials, preventing drug use among pupils and strengthening service represent the typical goals of LQ teacher workshops worldwide. In Finland, the LQ teacher training typically spans two days. Workshop trainers qualify as professionals after participating in a multi-phased training that includes practicing LQ workshop delivery and receiving guidance from an experienced trainer. Each LQ country selects a senior trainer who is responsible for implementing international LQ curriculum appropriate to the national context. Hence, local circumstances, such as the school system, culture and legislation, represent important factors in the implementation process.

\subsection{Research on Teacher Training on Social and Emotional Learning}

In order to implement SEL efficiently in schools, teachers need knowledge about SEL and the ability to apply it to practical classroom situations. Therefore, we conducted a systematic literature review of the ERIC, EBSCO and PsycINFO databases to inventory existing articles and studies on teacher SEL. The keywords for the search included the following: interaction skill(s), social and emotional skill(s), socio-emotional skill(s), social skill(s), emotional skill(s), inter-personal skill(s), teacher(s), instruct (or) and educator(s). In the ERIC and EBSCO database searches, we ignored articles with the keywords disability, disabilities, special education, educator or autism, autistic, asthma and ADHD. In addition, we applied the following limits to the PsycINFO database search: human, English language and non-disordered populations. Since a similar literature review was performed in 2010 (Talvio, 2014), we limited the publication year of articles in this query to those appearing between 2010 and 2015.

According to Talvio (2014), a database search in 2010 resulted in six publications from the educational sector. From these, only one, that by Barton-Arwood, Morrow, Lane and Jolivette (2005), proved relevant. Our search of publications from 2010 through 2014 also uncovered a single relevant article (Jennings, Frank, Snowberg, Coccia and Greenberg 2013). In their study, Jennings et al. (2013) described Cultivating Awareness and Resilience in Education (CARE for Teachers), which is a mindfulness-based professional development program designed to reduce stress and improve teacher performance. A randomized controlled trial examined program efficacy and acceptability among a sample of 50 teachers randomly assigned to CARE or to the waitlist control condition. Participants completed a battery of self-report measures before and after the intervention to evaluate the impact of the CARE program on general well-being, efficacy, burnout/time pressure and mindfulness. In that study, participation in the CARE program resulted in significant improvements in teacher well-being, efficacy, burnout/time-related stress and mindfulness when compared to controls. Teacher evaluations showed that they viewed CARE as a practical, acceptable and efficient method for reducing stress and improving performance. The results from this study suggest that the CARE program holds promise in supporting teachers who work in demanding settings and may improve the classroom environment (Jennings et al., 2013).

Thus, it appears that studies on developing teachers' social and emotional competence remain scarce. However, a growing body of evidence recommends implementing SEL in school settings (Durlak et al., 2011; Elias, Zins, Graczyk, 
\& Weissberg, 2003; Greenberg et al., 2003; Humphrey, 2013; Jennings et al., 2013; Jennings \& Greenberg, 2009; Talvio, 2014; Zins, Weissberg, Wang, \& Walberg, 2004; Zins, Payton, Weissberg, \& O'Brien, 2007). Indeed, several primary prevention programs were developed for teaching self-control, social competence, positive peer relations and interpersonal problem solving (Collaborative for academic, social and emotional learning, 2014). However, these programs focus on teaching these skills to students and do not provide explicit instructions to promote social and emotional literacy among teachers (Iizuka, Barrett, Gillies, Cook, \& Marinovic, 2014). Rather, they assume that the teacher is prepared to act as an effective emotional coach and role model (Jennings \& Greenberg, 2009). This may have resulted in a limited body of research on promoting teachers' social and emotional competence. Regardless, our literature review revealed that in education very few studies on in-service teacher SEL or the effectiveness of continuous training focused on SEL exist.

\subsection{Measuring the Outcomes of SEL and LQ Teacher Workshop}

As stated previously, measuring the development of teacher SEL remains important yet complex. Perhaps this explains why few measurement instruments exist and studies evaluating teacher SEL remain scarce. According to our previous findings (Talvio, Lonka, Komulainen, Kuusela, \& Lintunen, 2013; Talvio, Ketonen, \& Lonka, 2014; Talvio, Lonka, Komulainen, Kuusela, \& Lintunen, 2015; Talvio, 2014), teachers learned the central concepts taught during the SEL intervention course and could, using paper and pen, apply the skills studied to specific contexts. Furthermore, teachers participating in the SEL course retained the central concepts and skills nine months after completing the training. Participants also evaluated the usefulness of the training by describing their application of the skills studied to practical settings (Talvio et al., 2014).

In the above-mentioned studies, Kirkpatrick \& Kirkpatrick's (2006) four-phase model served as the basis for evaluations of the training, including participant reactions, knowledge, skills and overall well-being. This model was used since it approaches learning from various perspectives, whereas such evaluations typically only analyze reactions to training. However, analyzing feedback alone does not reveal much about learning specifically. For example, learning may be difficult, and reactions to a course in such cases may be negative. Thus, stepping beyond one's comfort zone may be required during learning and not all reactions may be positive. In turn, if evaluations limit their scope to only participant knowledge, little about the applicability of the training is revealed. If overall well-being is measured in addition to reactions, knowledge and applied knowledge, additional information about the benefits to and learning among training participants is elicited (Kirkpatrick \& Kirkpatrick, 2006).

Typically, training outcomes - such as positive reactions, the increase in knowledge and the developed behavior among participants - represent predictors of high-quality training (Colquitt, LePine, \& Noe, 2000). Indeed, Kirkpatrick and Kirkpatrick's (2006) model provides key information related to learning the subject studied. In addition, Jennings and Greenberg (2009) prefer applying a research design that includes pre- and post-test measures and a control group in order to ensure that any change detected resulted from the specific intervention. However, researchers must also recognize, for example, the personal disposition a participant brings to the instructional situation and how this relates to the effectiveness of such training (Colquitt et al., 2000; Tannenbaum \& Yukl, 1992). For example, interest plays a crucial role in learning and developing expertise (Silvia, 2008). According to expectancy-value theory (Eccles \& Wigfield, 2002; Wigfield \& Eccles, 2000), expectancies and values influence one's performance, such as through participation in an upcoming course. Eccles and Wigfield (2002) found that expectancies refer to beliefs about how a learner performs on different activities, while values refer to the reasons for completing an activity. Expectancies are determined by two factors: expectancies for success and subjective task values. Expectancies for success evaluate the participant's perceived competence in terms of performance. Subjective task values consist of four components: attainment value, intrinsic value, utility value and cost (Eccles \& Wigfield, 2002; Wigfield \& Eccles, 2000). Thus, expectancies and values influence participant decisions to attend or not attend training workshops as well as decisions during a training program. They also predict participants' levels of engagement, interest and academic success. Accordingly, expectancies and values affect participant performance, as well as SEL outcomes.

In addition, evaluating participants' values and expectancies may reveal their willingness to practically apply the knowledge and skills studied to the workplace setting after training. While school curriculum and teacher manuals typically define training content quite precisely, emphasis is ultimately determined by teachers, particularly in terms of how strongly specific learning goals are emphasized. For example, some mathematics teachers may identify their pupils' group skills as quite important during a lesson, while others may feel that mathematics is the only relevant content they teach and feel uncomfortable or incompetent in teaching anything beyond that particular subject matter. Therefore, exploring possible changes in teacher motivation vis-à-vis the goals of LQ during a teacher workshop remains important. If teachers participating in an LQ workshop consider the content important and motivating, they are more likely to implement LQ skills and concepts in their own classroom. In this case, it then follows that LQ successfully achieved its goal. 


\subsection{Research Questions}

The current study represents the first in a series aimed at investigating teachers' potential learning through their participation in an LQ workshop. Qualitative analysis of changes in participant knowledge and the application of such knowledge will be reported elsewhere (Berg, Talvio, \& Lonka, 2015). In this quantitative study, we investigated teachers' perceptions of the importance of and their competence related to LQ goals. In addition, teachers' task values, consisting of the attainment, intrinsic and utility values and cost, were analyzed. Accordingly, we addressed the following research questions:

1) During the teacher LQ workshop:

- do teachers' perceptions of the importance of the LQ goals change?

- do teachers' experienced competence on delivering instruction on the LQ topics studied change?

- do teachers' task values about the type of LQ training change?

2) Are there differences in the results between the intervention and comparison groups?

\subsection{Study Context}

In general, teachers are well educated in Finland. Preschool and elementary school teachers hold a Master's degree in pedagogy, while secondary school subject-matter teachers hold a Master's degree in the specific subject they teach (e.g., mathematics) as well as pedagogical studies. Despite increasing government encouragement in recent years to engage in $21^{\text {st }}$ century skills and promote positive youth development at school in Finland, teacher training institutes offer precious few possibilities for such training. Continuing education for teachers is thus an important way to prepare for the future. Due to the high-level of training Finnish teachers complete and the need for training on contemporary skills, Finland provides an interesting environment in which to carry out research of this type.

\section{Method}

\subsection{Procedures and Participants}

In this study, we examined the effects of the LQ intervention on teachers. We collected data from the intervention group before and after LQ workshops took place in different parts of Finland in autumn 2014. The content of each workshop was roughly equivalent and was conducted by certified LQ trainers using the official LQ course design. The two-day training workshops were held off campus during teachers' normal working hours. The pre- and post-test data from the first comparison group were collected in a similar manner: the pre-test was completed on the morning of the first day, while post-test data were gathered on the afternoon of the following day.

In total, 153 comprehensive school teachers and other staff members participated in LQ. On average, they had 10 years of work experience $(S D=7.9)$. The first comparison group consisted of 61 staff members from Finnish comprehensive schools not participating in the LQ training, and included volunteers who were not systematically randomized, with a mean of 16 years of work experience $(S D=10.6)$. The missing value per participant was under $30 \%$ and per variable it was under $5 \%$.

When comparing the intervention group to the first comparison group, we found that the first comparison group did not fully correspond to the intervention group. We performed a $\chi^{2}$ and found significant differences between the intervention and first comparison group with regards to gender $(\mathrm{p}=0.004)$, years of work experience $(\mathrm{p}=0.005)$ and job titles $(\mathrm{p}=0.003)$. Therefore, we controlled for these background characteristics in the repeated measures analyses.

In order to analyze the possible effects of the pre-test on the post-test responses, we collected additional data from 46 teachers with an average of 12 years' work experience $(S D=9.1)$. This second comparison group completed the questionnaire only once. With regards to background characteristics, we found no significant differences between the second comparison group and other groups (Table 1).

Table 1. Participant characteristics

\begin{tabular}{lcccccc}
\hline & \multicolumn{2}{c}{ Intervention group } & \multicolumn{2}{c}{ First comparison group } & \multicolumn{2}{c}{ Second comparison group } \\
& $\mathrm{n}$ & $\%$ & $\mathrm{n}$ & $\%$ & $\mathrm{n}$ & $\%$ \\
\hline Class teachers & 71 & 46 & 20 & 33 & 21 & 48 \\
Subject-matter teachers & 24 & 16 & 24 & 39 & 9 & 20 \\
Special teachers & 30 & 20 & 8 & 13 & 7 & 16 \\
Others & 28 & 18 & 9 & 15 & 7 & 16 \\
Total & 153 & 100 & 61 & 100 & 44 & 100 \\
& & & & & & \\
Female & 139 & 91 & 46 & 75 & 40 & 91 \\
Male & 14 & 9 & 15 & 25 & 4 & 9 \\
Total & 153 & 100 & 61 & 100 & 44 & 100 \\
\hline
\end{tabular}




\subsection{Ethical Considerations}

We informed all participants how their privacy would be protected and that their information and responses would remain anonymous. Participants were also informed about the possibility of withdrawing their responses from this study at any time without advance warning or explanation. None of the participants asked that their answers be removed from the database.

\subsection{Measures}

In the LQ questionnaire, teachers' perceptions of the LQ goals were approached from two perspectives: namely, how participants experienced the importance of the goals and their perceived competence in promoting the LQ goals. To measure these, participants rated eight statements we developed using a seven-point Likert scale with response options ranging from "not at all important" (1) to "very important" (7) or "totally disagree" (1) to "totally agree" (7). Examples of statements used to measure participants' perceptions of the importance of LQ included "It is the teacher's duty to teach interactive skills such as listening and conversation skills" and "It is the teacher's duty to motivate students to live a healthy lifestyle". We investigated teachers' perceived competence in promoting the LQ goals using statements such as "I am very skilled at teaching interactive skills such as listening and conversation skills" and "I am very skilled at motivating students to live a healthy lifestyle". In addition, eight statements regarding participant interest, task values, challenges, perceived usefulness and the cost of LQ types of training were evaluated using a seven-point Likert scale where response options ranged from "totally disagree" to "totally agree".

To consolidate information collected through the questionnaire, we performed an exploratory factor analysis using data from the post-test responses. Table 2 shows the final list of variables we used in our analysis, their internal consistencies and the number of items for each variable.

\subsection{Data Analysis}

To examine the gain scores between and within groups and to statistically control for some background characteristics, we used the repeated measures ANOVA (GLM) given its ability to perform overall comparisons and the specified follow-up comparisons in one step. In our analysis, we used SPSS version 22.

\section{Results}

Table 2 shows that the mean values for the post-test scores were higher than the pre-test scores for all of the variables measured among the intervention group. We found that the pre-test values across all variables measuring perceived competence were lower for the intervention group compared to those for the first comparison group, whereas the intervention group scored higher across all variables measuring perceived importance except for the importance of promoting a healthy lifestyle among students, where the intervention group and the first comparison group scored equally high. Among the first comparison group, the mean values for the post-test scores were also higher than the pre-test values for all variables measuring perceived competence $(1 b, 2 b, 3 b$ and $4 b)$, while the post-test scores for all variables measuring perceived importance (1a, 2a, 3a and 4a) and perceived task value (5) were lower than the pre-test scores.

Among the second comparison group, the mean values across all variables were lower than the post-test scores of the intervention group. If we compare the mean values of the second comparison group to the post-test scores of other groups, we find that the mean values were lowest for the second comparison group for three variables ( $3 a, 1 b$ and $3 b$ ). For other variables, the mean values of the second comparison group fell between the post-test scores of the other groups.

When controlling for the possible effects of gender, years of work experience and job title, we found that female participants scored significantly higher than male participants when asked about their perceived skills in promoting student SEL (2b) ( $p=0.02, d=0.32)$. Other background characteristics carried no influence on other variables.

First, we summarize the gain scores analyzing whether the change is different between the intervention group and the first comparison group. Next, we look at the differences between groups at the first and second measurement points. Finally, we report the changes between the measurement points for both groups. Upon finding an unexpected relationship between scores for the intervention group and the first comparison group, we then use the second comparison group to determine the potential effect of the pre-test (see Kerlinger \& Lee, 2000, pp. 485-500). 
Table 2. Comparison of time 1 and time 2 among groups for the variables measured

\begin{tabular}{|c|c|c|c|c|c|c|}
\hline \multirow[b]{2}{*}{ Variable } & \multirow[b]{2}{*}{$\begin{array}{l}\text { Items } \\
\left(\alpha^{a}\right)\end{array}$} & \multicolumn{2}{|c|}{ Intervention group } & \multicolumn{2}{|c|}{ First comparison group } & \multirow{2}{*}{$\begin{array}{l}\text { Second } \\
\text { comparison } \\
\text { group } \\
\qquad M(S D)\end{array}$} \\
\hline & & $\begin{array}{l}\text { Time } 1 \\
M(S D)\end{array}$ & $\begin{array}{r}\text { Time } 2 \\
M(S D) \\
\end{array}$ & $\begin{array}{l}\text { Time } 1 \\
M(S D)\end{array}$ & $\begin{array}{l}\text { Time } 2 \\
M(S D) \\
\end{array}$ & \\
\hline \multicolumn{7}{|l|}{ Perveived Importance } \\
\hline $\begin{array}{l}\text { 1a Importance of creating a safe } \\
\text { learning environment }\end{array}$ & 1 & $6.93(0.27)$ & $6.95(0.21)$ & $6.89(0.32)$ & $6.84(0.42)$ & $6.91(0.29)$ \\
\hline $\begin{array}{l}\text { 2a Importance of promoting } \\
\text { student's SEL }\end{array}$ & $4(0.87)$ & $6.63(0.49)$ & $6.73(0.45)$ & $6.50(0.53)$ & $6.46(0.55)$ & $6.63(0.49)$ \\
\hline $\begin{array}{l}\text { 3a Importance of promoting a } \\
\text { healthy lifestyle among students }\end{array}$ & $2(0.89)$ & $6.00(0.98)$ & $6.29(0.83)$ & $5.97(1.10)$ & $5.88(0.99)$ & $5.84(1.08)$ \\
\hline $\begin{array}{l}\text { 4a Importance of teaching } \\
\text { students to help others }\end{array}$ & 1 & $6.46(0.84)$ & $6.73(0.51)$ & $6.46(0.70)$ & $6.31(0.74)$ & $6.43(0.76)$ \\
\hline \multicolumn{7}{|l|}{ Perveived Competence } \\
\hline $\begin{array}{l}\text { 1b Perceived skills in creating a } \\
\text { safe learning environment }\end{array}$ & 1 & $5.29(0.79)$ & $5.84(0.74)$ & $5.52(0.85)$ & $5.72(0.80)$ & $5.52(0.85)$ \\
\hline $\begin{array}{l}\text { 2b Perceived skills in } \\
\text { promoting student's SEL }\end{array}$ & $4(0.89)$ & $4.96(1.13)$ & $5.33(1.03)$ & $5.19(0.87)$ & $5.26(0.85)$ & $5.28(0.77)$ \\
\hline $\begin{array}{l}\text { 3b Perceived skills in } \\
\text { promoting a healthy lifestyle } \\
\text { among students }\end{array}$ & $2(0.81)$ & $4.66(1.06)$ & $5.10(1.06)$ & $4.80(0.98)$ & $4.91(0.86)$ & $4.73(1.01)$ \\
\hline $\begin{array}{l}\text { 4b Perceived skills in teaching } \\
\text { students to help others }\end{array}$ & 1 & $5.13(1.08)$ & $5.51(0.96)$ & $5.21(1.18)$ & $5.25(1.01)$ & $5.34(0.94)$ \\
\hline \multicolumn{7}{|l|}{ Task value } \\
\hline 5 Perceived task value & $6(0.90)$ & $5.44(0.68)$ & $6.34(0.53)$ & $4.73(1.33)$ & $4.68(1.29)$ & $5.12(1.09)$ \\
\hline
\end{tabular}

\subsection{Perceived Importance}

Figure 1a shows that, during LQ, the mean scores for responses related to the importance of creating a safe learning environment increased among the intervention group, whereas the mean scores decreased among participants in the first comparison group. These gains did not differ significantly between groups $(p=0.139, d=0.20)$ indicating that the differences between groups taken at both measurement points were not statistically significant. Furthermore, no difference was found at the first measurement point $(p=0.258, d=0.16$ ), although we found a significant difference at the second measurement point ( $p=0.006, d=0.38$ ). The changes between the pre- and post-test measurements were not significant for the intervention ( $p=0.428, d=0.11)$ or first comparison group $(p=0.210, d=0.17)$.

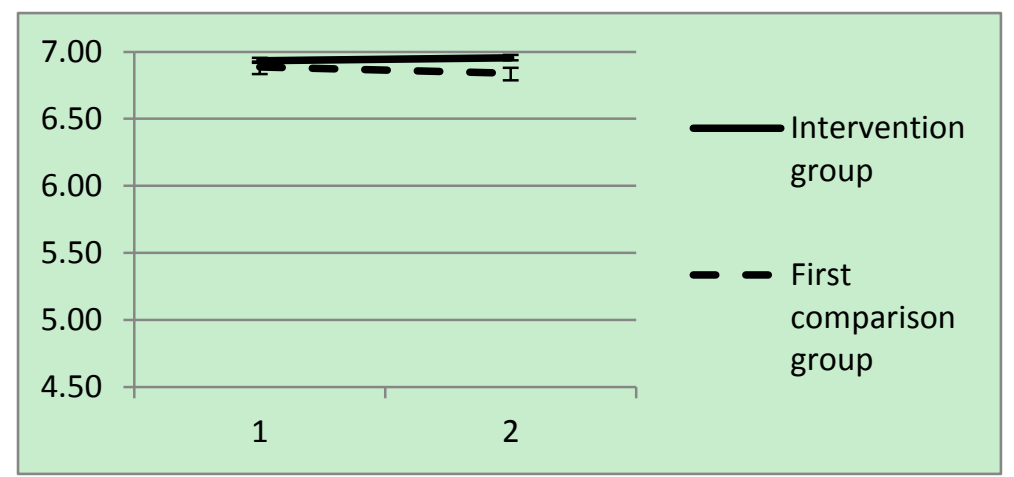

Figure 1a. Mean and 95\% CI values on the importance of creating a safe learning environment between pre- and post-test scores. The y-axis scale only includes values falling between 4.50 and 7.00.

Figure 2a shows that the mean value among the intervention group on the importance of promoting students' SEL increased during LQ, whereas the mean value decreased on the same measurement among those in the intervention 
group. Furthermore, the gain scores on the importance of promoting students' SEL differed significantly between groups $(p=0.005, d=0.39)$. The difference between groups on the pre-test scores was not significant $(p=0.093, d=$ 0.23 , while the difference in post-test scores was statistically significant $(p<0.001, d=0.51)$. The scores in the intervention group improved significantly $(p<0.001, d=0.53)$, while no significant change was found among the first comparison group $(p=0.337, d=0.13)$.

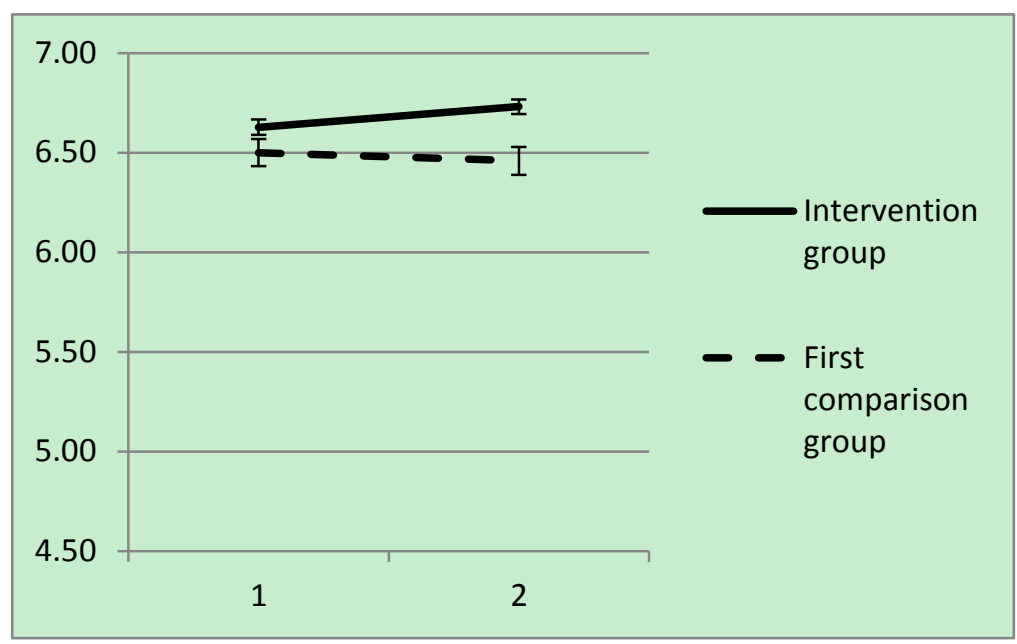

Figure 2a. Mean and 95\% CI values on the importance of promoting student SEL between pre- and post-test scores. The $\mathrm{y}$-axis scale only includes values falling between 4.50 and 7.00 .

The intervention group scored higher after LQ on the variable measuring the importance of promoting a healthy lifestyle among students. By contrast, the mean scores for the comparison group decreased between the two measurement points. Furthermore, the difference in the gain scores was significant $(p<0.001, d=0.52)$. However, we found no difference between groups on the pre-test scores $(p=0.846, d=0.03)$, but the difference between groups on the post-test scores was statistically significant $(p=0.002, d=0.43)$. The change in the pre- and post-test scores among the intervention group was significant $(p<0.001, d=0.74)$. Yet, we found no significant difference between the measurement points for the first comparison group $(p=0.304, d=0.14)$ (Figure 3a).

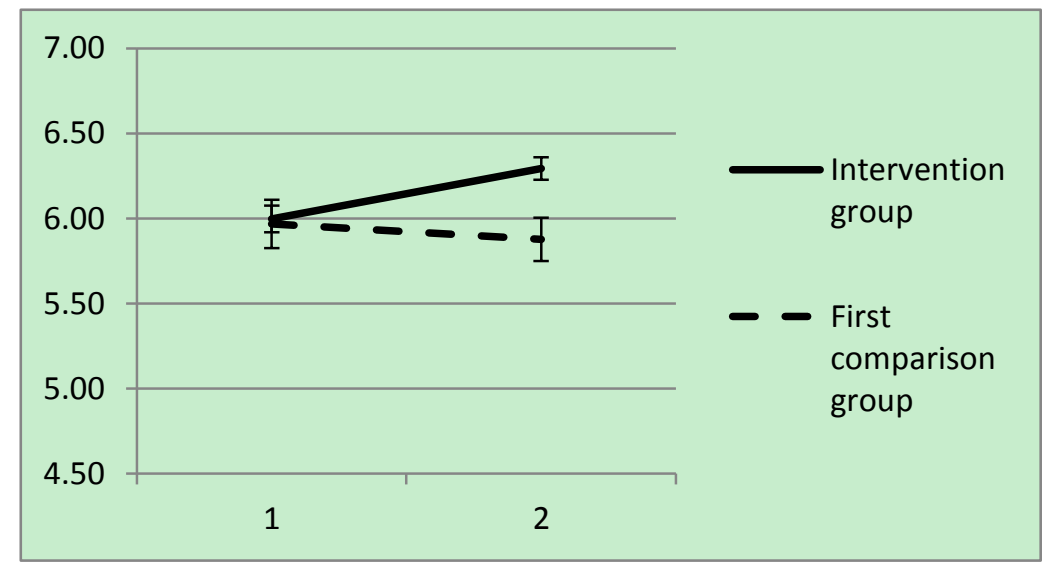

Figure $3 a$. Mean and $95 \%$ CI values on the importance of promoting a healthy life among students between pre- and post-test scores. The y-axis scale only includes values falling between 4.50 and 7.00.

The mean value among participants in the intervention group on the variable measuring the importance of teaching students to help others improved, whereas the mean value among the first comparison group decreased between the two measurement points (Figure 4a). The gains between the groups differed significantly $(p<0.001, d=0.60)$. The scores among the intervention and first comparison group on the pre-test measurement did not differ significantly $(p=0.976, d$ $=0.00)$. However, we found a significant difference between groups on the post-test scores $(p<0.001, d=0.65)$. Among the intervention group, the change in scores during training was significant $(p<0.001, d=0.73)$, whereas we found no change among the first comparison group between measurement points $(p=0.071, d=0.25)$. 


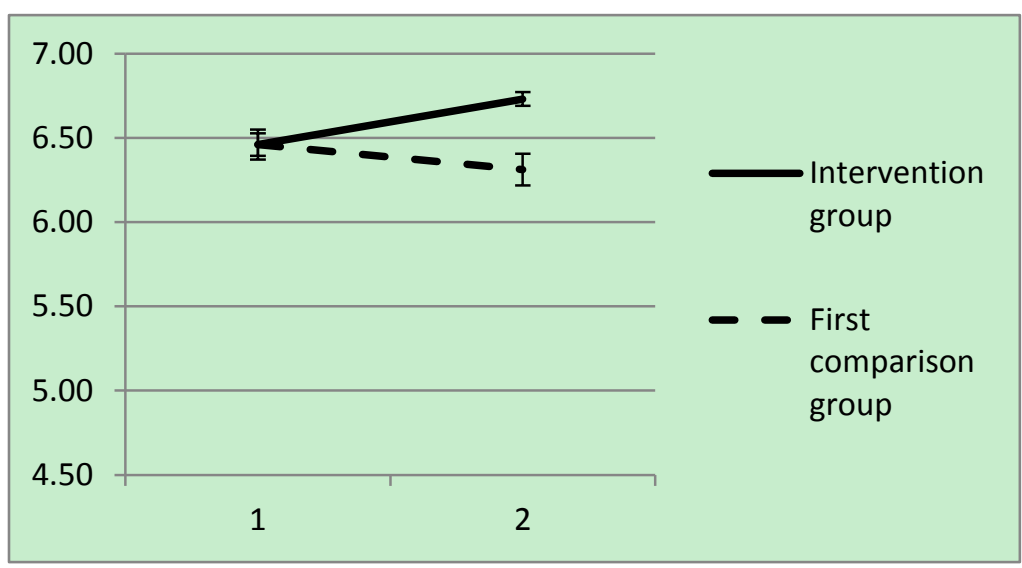

Figure 4a. Mean and 95\% CI values on the importance of teaching students to help others between pre- and post-test scores. The y-axis scale only includes values falling between 4.50 and 7.00.

\subsection{Perceived Competence in Promoting LQ Goals}

Figure $1 \mathrm{~b}$ shows that the scores for participants' perceived skills in creating a safe learning environment among both the intervention and the first comparison group improved between measurement points. In addition, the gain scores between groups differed significantly ( $p=0.001, d=0.46$ ). However, we found no difference between groups on the pre-test $(p$ $=0.059, d=0.26)$ or post-test scores $(p=0.294, d=.14)$. Within each group, the changes between measurement points were statistically significant for both the intervention $(p<0.001, d=1.35)$ and first comparison group $(p=0.027, d=$ 0.31). We also found a significant difference between the post-test scores for the intervention and second comparison groups $(p=0.016, d=0.40)$. No difference between the first and second comparison groups, however, was found $(p=$ $0.225, d=0.24$ ) (Figure 1b).

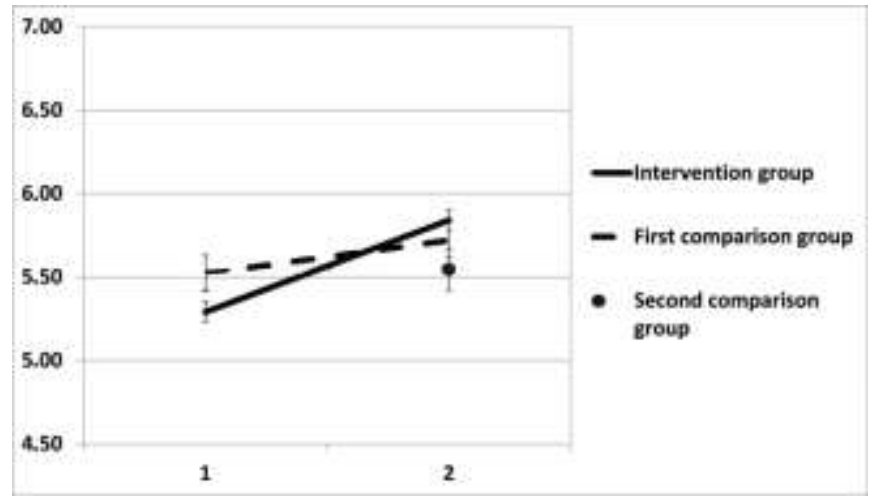

Figure $1 \mathrm{~b}$. Mean and 95\% CI values for perceived skills in creating a safe atmosphere for each group between the preand post-test scores. The y-axis scale only includes values falling between 4.50 and 7.00.

Both the intervention and the first comparison group scored higher at the second measurement point on their perceived skills in promoting student SEL (Figure 2b). The gains among the groups differed significantly $(p<0.001, d=0.45)$. The scores for the intervention and the first comparison group did not differ from each other at the first $(p=0.074, d=$ $0.25)$ or second measurement point $(p=0.543, d=0.08)$. However, the improvement was statistically significant both among the intervention group $(p<0.001, d=0.76)$ and the first comparison group $(p=0.397, d=0.12)$. When comparing the post-test scores, we found no difference between the intervention group and the second comparison group ( $p=0.207, d=0.21$ ) or between the first and second comparison groups $(p=.875, d=0.03)$. However, in the pre-test results, we found a significant difference between the second comparison group and the intervention group ( $p=$ $0.007, d=-0.46)$, but no difference between the two comparison groups $(p=0.386, d=-0.17)$. 


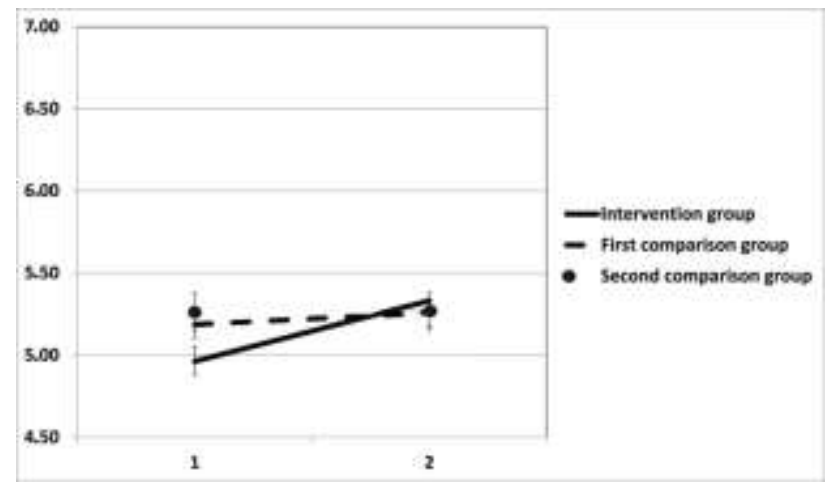

Figure $2 b$. Mean and $95 \%$ CI values for perceived skills in promoting student SEL for each group between pre- and post-test scores. The y-axis scale only includes values falling between 4.50 and 7.00.

Figure $3 \mathrm{~b}$ shows that the mean values for perceived skills in promoting a healthy lifestyle were higher at the second measurement point among both the intervention and the first comparison group. These gains differed significantly ( $p=$ $0.005, d=0.39)$. However, we found no significant differences between groups on the pre- $(p=0.365, d=0.12)$ and post-test scores $(p=0.202, d=0.18)$. The change across measurement points was significant, however, in the intervention group $(p<0.001, d=0.96)$, while no change was detected for the first comparison group $(p=0.308, d=$ $0.14)$.

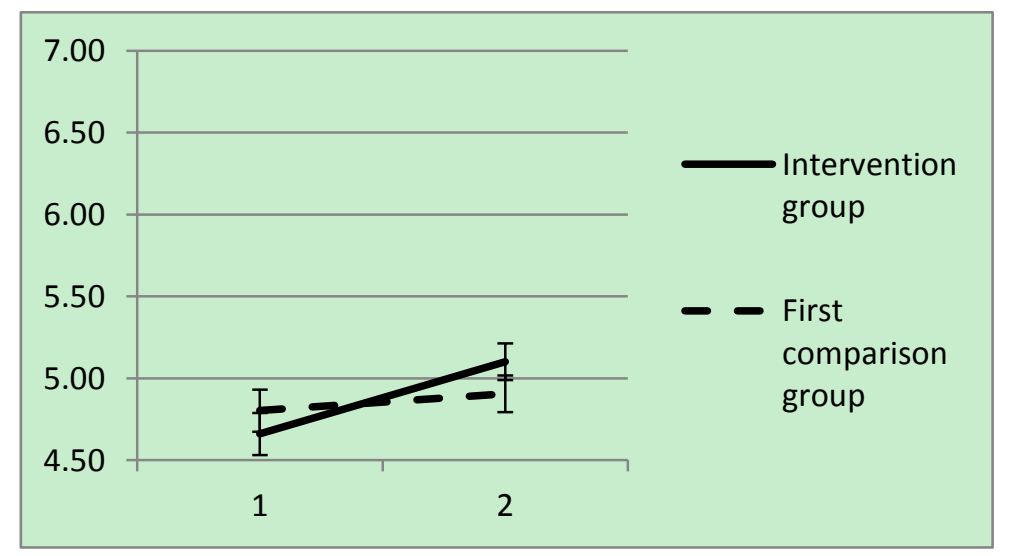

Figure $3 b$. Mean and 95\% CI values for perceived skills in promoting a healthy lifestyle among students between the pre- and post-test scores. The y-axis scale only includes values falling between 4.50 and 7.00.

In addition, both groups scored better at the second measurement point for the item evaluating perceived skills in teaching students to help others (Figure 4b). The gains were significantly different between groups $(p=0.030, d=$ $0.30)$. The differences between groups were not significant for the pre- $(p=0.658, d=0.06)$ and post-test scores $(p=$ $0.087, d=0.24)$. The change between the two measurement points was, however, statistically significant for the intervention group $(p<0.001, d=0.65)$. In the first comparison group, we found no change between the pre- and the post-test scores $(p=0.703, d=0.05)$. 


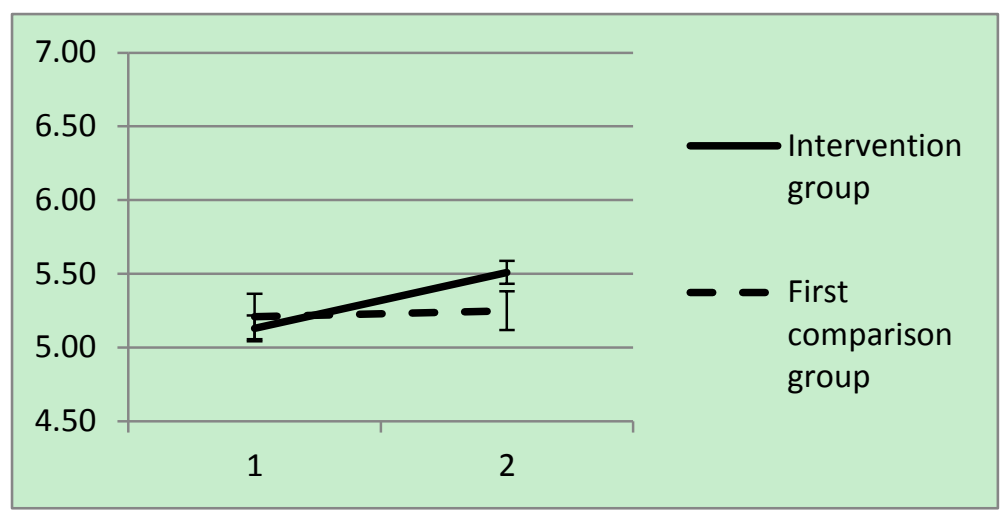

Figure $4 b$. Mean and 95\% CI values for perceived skills in teaching students to help others between the pre- and post-test scores. The y-axis scale only includes values falling between 4.50 and 7.00.

\subsection{Task Value}

Figure 5 shows that the intervention group improved their scores during the training on the perceived task value, whereas the comparison group scored lower at the post-test measurement point. The difference in gain scores for the perceived task values was statistically significant $(p<0.001, d=1.24)$. The difference between the intervention and the first comparison group was significant for both the pre- $(p<0.001, d=0.70)$ and post-test measurement points $(p<$ $0.001, d=1.83)$. Among the intervention group, the change between measurement points was also significant $(p<0.001$, $d=0.55)$. However, among the first comparison group, we found no difference between the pre- and post-test scores ( $p$ $=0.562, d=0.08$ ).

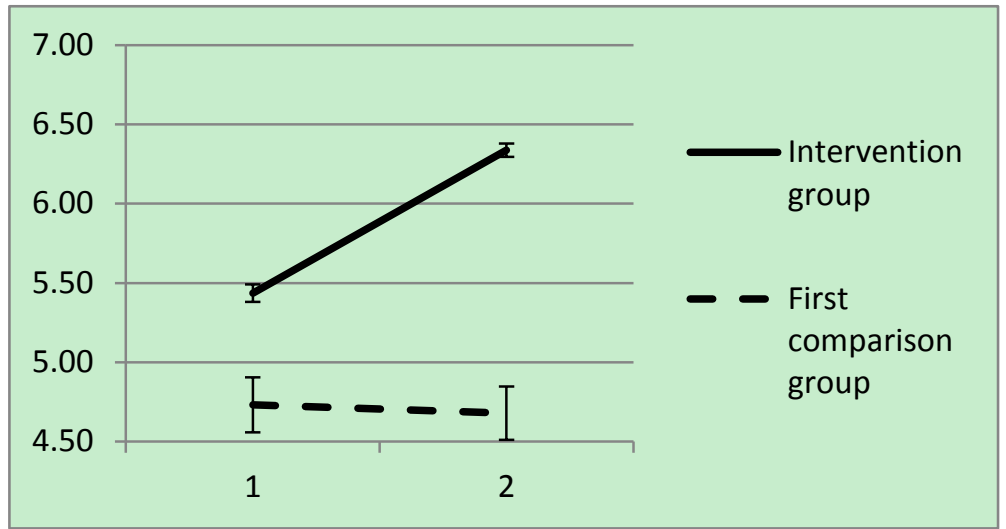

Figure 5. Mean and 95\% CI values for the perceived task value between pre- and post-test scores. The y-axis scale only includes values falling between 4.50 and 7.00 .

\section{Discussion}

In this study, we found significant differences in the gains for almost all variables, demonstrating a difference in the changes reported between the intervention group and the first comparison group. However, we found no difference in the scores for the variable measuring the importance of creating a safe learning environment. Further analyses revealed that the changes were significant due to a change in the intervention group. The current study found that teachers participating in the Lions Quest (LQ) teachers' workshop viewed the goals of the training as more relevant after the training than before it. In addition, since participants rated their competence in skills related to the LQ goals higher after the training, we may conclude that general learning of the content took place on nearly all of the areas measured among teachers participating in LQ.

While our results were quite clear, some interesting details warrant further discussion. First, we found no significant difference between the pre- and post-test scores or between the intervention and the first comparison group on our measurement of the importance of creating a safe learning environment. As illustrated in Table 2 and Figure 1a, the ceiling effect likely explains the consistency in scores across the training. Both groups rated this statement quite highly at the pre-test measurement point, while the change between the pre- and post-test scores remained quite small. It is likely that teachers already learned through practice, during teacher training or during some other follow-up course that creating a safe learning environment is important. Hence, the LQ training did not change their opinions on this specific 
issue. Another interesting detail lies in participants' perceived skills in creating a safe learning environment, where both groups found themselves significantly more competent after the training even though the perceived competence was stronger among participants in the intervention group. Further analyses among a second comparison group suggested that merely asking this question may result in a positive change in perceived competence without necessarily participating in a training course (Figure 1b). Thus, it may be that taking part in a pre-test measurement prompts teachers to reflect upon their knowledge and skills. Consequently, during post-test measurement on the following day, they become more aware of their competence regarding creating a safe learning environment. When a question pertains to such an abstract phenomenon, first asking about it and then subsequently allowing participants time to think about it may allow them to recognize their own knowledge and skills.

With regards to perceived skills in promoting student SEL (Figure 2b), both the intervention group and the first comparison group scored significantly better on the post-test measurement than on the pre-test measurement. In this case, we found no statistical differences in the post-test scores between groups. Thus, responding to the pre-test measurement did not explain the change in scores among participants in the first comparison group. However, when comparing the pre-test results, we found that the second comparison group scored higher than the other groups. It may be that teachers evaluate their competence in supporting their students' SEL quite well. While teachers' perceptions of SEL were determined by asking four questions which carried a solid internal consistency, teachers did not identify what we hoped they would. Thus, the complexity of SEL as a phenomenon may have influenced the responses among those who did not participate in the training. It was also interesting that gender explained the changes in scores across measurement points for this variable. This finding is similar to findings from medical education. According to a review article by Aspegren (1999), men learn communication skills more slowly than women.

Of particular interest, we noted that all of the pre-test scores for teachers' perceived competence were lower among the intervention group than among the comparison groups. It is likely that teachers who attended the course felt that they needed to improve their skills, whereas the members of the comparison groups may feel that they possess sufficient LQ skills and saw no need to participate in additional training. This supports the conclusion that teachers from the comparison groups did not necessarily possess a clear understanding of their own competence based on information in the questionnaire.

This study's limitations include the rather small number of participants included in the first comparison group. However, since it is quite difficult to motivate teachers to complete a questionnaire twice within two days without participating in a workshop, we would expect a smaller number of participants in the comparison groups compared to the intervention group. This study is also limited by our inability to investigate whether teachers participating in LQ subsequently implement the skills they learn into practice. On the other hand, implementation of the program in the classroom does not depend solely on the quality of a teacher workshop, but also relies on school policy and administration (Humphrey, 2013). In this study, we attempted to investigate teacher learning during LQ, which might affect but not guarantee implementation.

Despite these limitations, our study provides some key insights. Investigating perceived importance, competence and value allows us to investigate learning through short courses such as LQ relatively well. Behavior change is a long, slow process, where observation or video recording would not necessarily show any change in teacher behavior. Collecting and analyzing such data from a large number of participants is also rather laborious. Similarly, collecting data regarding changes in teacher knowledge and skills after training does not guarantee the skills they learned will be applied to the classroom setting. As such, this study explored changes in teachers' experienced importance and perceived competence towards the LQ goals and the perceived value of such courses as likely indicators of teacher readiness to change.

It is important to realize that measuring participants' reactions, knowledge and applied knowledge alone does not necessarily provide a full picture of the outcomes from a two-day LQ teacher workshop. First, examining teacher perceptions of their own importance and competence regarding the subjects studied is key. If a teacher attaches a low level of importance and a high level of competence to a particular subject, they may not be motivated to learn more about it. If they, in turn, experience a high level of importance and a low level of competence, they may be motivated to learn more and change their behavior. We know, for instance, that attaching new concepts and theories to existing knowledge and skills requires time and practice. Therefore, it is essential to identify what changes take place vis-à-vis teachers' perceived importance and competence regarding specific training goals. If teachers attach a higher importance to the concepts and theories studied and feel more competent after completing training, they are more likely to learn and more motivated to apply the new knowledge and skills on a practical level.

While Lions Quest in Finland appears to be successful with regards to the learning outcomes of participants in general, our results indicate that male teachers did not perform as well as their female counterparts in promoting their students' SEL. It may be important to develop a tool, such as a technical application, to interest men in particular to implement 
their skills after participation in a LQ teachers' workshop.

The participants of this study were from Finland where teacher training is lengthy and of an exceptionally high quality. While the topics studied in the LQ course should be familiar to participants, they may still benefit from LQ in multiple ways. We, thus, conclude that the Finnish Lions Quest succeeded in bringing something unique and necessary to teacher continuing education. Future research should focus on comparing how teachers in other countries benefit from the LQ teacher workshops, where teacher training and the school culture are different. Future studies should also include how LQ is implemented in the classroom and in schools. Teacher motivation and skills do not necessarily guarantee an ability to teach such skills in the classroom. For example, if academic success is the only goal assessed, teachers may concentrate instead on $21^{\text {st }}$ century skills in order to teach specific subjects.

It is, therefore, important that school policy promotes the development of society. This body of research demonstrates that LQ represents a practical tool for schools by assisting teachers in updating their knowledge and skills necessary for the future.

\section{Acknowledgements}

This study was partially funded by the Lions Clubs International Foundation. We would also like to thank Dr. Fernando Salazar for his contribution to this manuscript.

\section{References}

Ananiadou, K., \& Claro, M. (2009). 21st century skills and competences for new millennium learners in OECD countries. Paris: Centre for Educational Research and Innovation (CERI)-New Millennium Learners. http://dx.doi.org/10.1787/218525261154

Aspegren, K. (1999). BEME guide no.2: Teaching and learning communication skills in medicine--a review. Medical Teacher, 21(6), 563-570. http://dx.doi.org/10.1080/01421599978979

Barton-Arwood, S., Morrow, L., Lane, K., \& Jolivette, K. (2005). Project IMPROVE: Improving teachers' ability to address students' social needs. Education and Treatment of Children, 28(4), 430-443.

Berg, M., Talvio, M., \& Lonka, K. (2015). A qualitative study on the change of teachers' knowledge and the applied knowledge during the Lions Quest program. Manuscript in preparation.

Collaborative for academic, social and emotional learning. (2014). Implementation » overview. Retrieved from http://www.casel.org/implement/index.php

Colquitt, J. A., LePine, J. A., \& Noe, R. A. (2000). Toward an integrative theory of training motivation: A meta-analytic path analysis of 20 years of research. Journal of Applied Psychology, 85(5), 678-707. http://dx.doi.org/10.1037/0021-9010.85.5.678

Durlak, J. A., Weissberg, R. P., Dymnicki, A. B., Taylor, R. D., \& Schellinger, K. B. (2011). The impact of enhancing students' social and emotional learning: A Meta - Analysis of School - Based universal interventions. Child Development, 82(1), 405-432. http://dx.doi.org/10.1111/j.1467-8624.2010.01564.x

Eccles, J. S., \& Wigfield, A. (2002). Motivational beliefs, values, and goals. Annual Review of Psychology, 53(1), 109-132. http://dx.doi.org/10.1146/annurev.psych.53.100901.135153

Elias, M. J., Zins, J. E., Graczyk, P. A., \& Weissberg, R. P. (2003). Implementation, sustainability, and scaling up of social-emotional and academic innovations in public schools. School Psychology Review, 32(3), 303-320.

Greenberg, M. T., Weissberg, R. P., O Brien, M. U., Zins, J. E., Fredericks, L., Resnik, H., \& Elias, M. J. (2003). Enhancing school-based prevention and youth development through coordinated social, emotional, and academic learning. American Psychologist, 58(6/7), 466-474. http://dx.doi.org/10.1037/0003-066X.58.6-7.466

Humphrey, N. (2013). Social and emotional learning: A critical appraisal. London: SAGE Publications Limited. http://dx.doi.org/10.4135/9781446288603

Iizuka, C. A., Barrett, P. M., Gillies, R., Cook, C. R., \& Marinovic, W. (2014). A combined intervention targeting both teachers' and students' social-emotional skills: Preliminary evaluation of students' outcomes. Australian Journal of Guidance and Counselling, 24(02), 152-166. http://dx.doi.org/10.1017/jgc.2014.12

Jennings, P. A., Frank, J. L., Snowberg, K. E., Coccia, M. A., \& Greenberg, M. T. (2013). Improving classroom learning environments by cultivating awareness and resilience in education (CARE): Results of a randomized controlled trial. School Psychology Quarterly, 28(4), 374-390. http://dx.doi.org/10.1037/spq0000035 
Jennings, P. A., \& Greenberg, M. T. (2009). The prosocial classroom: Teacher social and emotional competence in relation to student and classroom outcomes. Review of Educational Research, 79(1), 491-525. http://dx.doi.org/10.3102/0034654308325693

Kerlinger, F. N., \& Lee, H. B. (2000). Foundations of behavioral research (4th ed.). Fort Worth (Tex.): Harcourt College Publishers

Kirkpatrick, D. L., \& Kirkpatrick, J. D. (2006). Evaluating training programs: The four levels (Third ed.). San Francisco, CA: Berrett-Koehler Publishers, Inc.

Lions Quest. (2015). Retrieved from http://www.lions-quest.org/

Silvia, P. J. (2008). Interest-The curious emotion. Current Directions in Psychological Science, 17(1), 57-60. http://dx.doi.org/10.1111/j.1467-8721.2008.00548.x

Talvio, M. (2014). How do teachers benefit from training on interaction skills? Developing and utilising an instrument to evaluate teachers' social and emotional learning (Doctoral dissertation). https://helda.helsinki.fi/handle/10138/136437

Talvio, M., Berg, M., \& Lonka, K. (2015). How does Continuing Training on Social Interaction Skills Benefit Teachers? Procedia-Social and Behavioral Sciences, 171, 820-829. http://dx.doi.org/10.1016/j.sbspro.2015.01.197

Talvio, M., Ketonen, E., \& Lonka, K. (2014). How long lasting are the effects of training on interaction skills? Teachers' sample. Proceedings of 2014 International Conference on Advanced Education and Management (ICAEM2014) $125-131$.

Talvio, M., \& Lonka, K. (2013). International variation in perceiving goals of a youth development programme (Lions Quest). The European Journal of Social \& Behavioural Sciences, 6(3), 1057-1065. http://dx.doi.org/10.15405/ejsbs.82

Talvio, M., Lonka, K., Komulainen, E., Kuusela, M., \& Lintunen, T. (2013). Revisiting Gordon's Teacher Effectiveness Training: An Intervention Study on Teachers' Social and Emotional Learning. Electronic Journal of Research in Educational Psychology, 11(3), 693-716. http://dx.doi.org/10.14204/ejrep.31.13073

Talvio, M., Lonka, K., Komulainen, E., Kuusela, M., \& Lintunen, T. (2015). The development of teachers' responses to challenging situations during interactions training. Teacher Development, 19(1), 97-115. http://dx.doi.org/10.1080/13664530.2014.979298

Tannenbaum, S. I., \& Yukl, G. (1992). Training and development in work organizations. Annual Review of Psychology, 43(1), 399-441. http://dx.doi.org/10.1146/annurev.ps.43.020192.002151

The Finnish National Board of Education (2014). The national core curriculum in basic education 2014 [Perusopetuksen opetussuunnitelman perusteet 2014]. http://www.oph.fi/download/163777_perusopetuksen_opetussuunnitelman_perusteet_2014.pdf

Wigfield, A., \& Eccles, J. S. (2000). Expectancy-Value theory of achievement motivation. Contemporary Educational Psychology, 25(1), 68-81. http://dx.doi.org/10.1006/ceps.1999.1015

Zins, J. E., Payton, J. W., Weissberg, R. P., \& O'Brien, M. U. (2007). Social and emotional learning and successful school performance. In G. Matthews, M. Zeidner \& R. D. Roberts (Eds.), The science of emotional intelligence: Knowns and unknowns (pp. 376-395). New York: Oxford University Press.

Zins, J. E., Weissberg, R. P., Wang, M. C., \& Walberg, H. J. (Eds.). (2004). Building academic success on social and emotional learning: What does the research say? New York: Teachers College Press.

This work is licensed under a Creative Commons Attribution 3.0 License. 